WellBeing International

WBI Studies Repository

2019

\title{
Building a Vegan Feminist Network in the Professionalized Digital Age of Third Wave Animal Activism
}

Corey Lee Wrenn

University of Kent at Canterbury, corey.wrenn@gmail.com

Follow this and additional works at: https://www.wellbeingintlstudiesrepository.org/divsmov

Part of the Animal Studies Commons, Civic and Community Engagement Commons, and the Politics and Social Change Commons

\section{Recommended Citation}

Wrenn, C. L. (2019). Building a Vegan Feminist Network in the Professionalized Digital Age of Third Wave Animal Activism. DOI: 10.31235/osf.io/jtps8

This material is brought to you for free and open access by WellBeing International. It has been accepted for inclusion by an authorized administrator of the WBI Studies Repository. For more information, please contact wbisr-info@wellbeingintl.org.

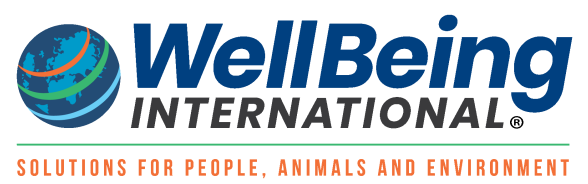




\author{
Dr. Corey L. Wrenn \\ University of Kent \\ School of Social Policy, Sociology, and Social Research \\ Canterbury, England
}

Completed: July, 2018

Accepted Presentation: February 1, 2019

Conference: American Sociological Association Annual Meeting, August 12, 2019

\title{
Building a Vegan Feminist Network in the Professionalized Digital Age of Third Wave Animal Activism
}

\begin{abstract}
Despite its legacy of feminist leadership and a continued female majority, the Nonhuman Animal rights movement has exhibited structural sexism across its various waves of protest. This institutionalized sexism not only inhibits women's ability to protest safely and effectively, but also permeates the activist imagination and aggravates interpersonal violence. Even Nonhuman Animals as a feminized group are unwittingly disparaged in popular campaigns. This essay suggests that structural sexism in the Nonhuman Animal rights movement is nourished by its patriarchal organization, specifically its decision to professionalize. Twenty-first century vegan feminist activism on the margins has been able to circumvent the hegemony of professionalized power and challenge taken-for-granted bureaucratic structures. Yet, despite indications that vegan feminist activists are influencing the movement dialogue, the movement's patriarchal norms have encouraged considerable pushback. Indeed, the patriarchal influence of professionalization has even created division between second wave and third wave vegan feminists.
\end{abstract}

\section{Introduction}

The Nonhuman Animal ${ }^{1}$ rights movement was founded on the labor of hundreds of women ${ }^{2}$ in the $19^{\text {th }}$ century, many of whom were explicitly conscious of the connections between their own oppression and that of other animals (Beers 2006). This first wave of vegan feminism in the West thrived with the endeavors of Annie Besant, Frances Power Cobb, Margaret Damer Dawson, Charlotte Despard, Lind af Hageby, and others. ${ }^{3}$ These women forged charities and shelters, negotiated pioneering legislation, and established a basic societal recognition that Nonhuman Animals are sentient and deserve care and attention. Sparked by the social upheaval of the late industrial revolution, multiple wars and rebellions, and Progressive Era initiatives, these women saw anti-speciesism as deeply relevant to social justice efforts (Kean 1998).

\footnotetext{
${ }^{1}$ I capitalize this term as a politicized reference to the nonhuman diaspora struggling under human supremacy.

${ }^{2}$ Throughout this chapter I use the term "women" to refer to female-identified persons, cis, trans, or non-binary as appropriate.

${ }^{3}$ A timeline of vegan feminist leaders across all three waves is hosted on Name of Organization at http://websiteanonymized
} 
Indeed, this intersectional praxis and female predominance was indicative of an inherent feminist element to the movement's formative years.

Animal activism of the $20^{\text {th }}$ century was also influenced by concurrent movements, adopting contemporary concepts of civil rights, grassroots mobilization, and the personal as political. Second wave activists rallied in a society that now recognized the moral importance of animal welfare but, paradoxically, had also industrialized animal suffering on a large scale. Strategies of this era involved a resistance to this industrialization, specifically in the industries of vivisection and factory farming. In doing so, these activists furthered the notion that vegetarianism (and sometimes veganism) was an important component to resisting speciesism and a variety of other social ills. The emphasis on compassion and community campaigning ensured that women remained in the majority, but the formal establishment of the movement since the late $19^{\text {th }}$ century entailed a steady encroachment of male leadership.

This establishment gradually transformed into a strategy of formal incorporation whereby the autonomous and community-based grassroots collectives of the 1970s and 80s became staterecognized nonprofits (McCarthy and Zald 1973). While many of these charities were femaleheaded, many more were not. Indeed, the hierarchical nature of most organizations inevitably disempowered and disadvantaged women, and the movement took on an increasingly male face (Kheel 1985). While first wave women activists boldly entered the public sphere to do women's work in a man's world, many second wave women found themselves shut out and shut up as the movement went corporate. This is not to abscond women from culpability. Sociological research has uncovered that anti-speciesist activists of all genders willingly suppress stereotypically feminine behavior and promote a masculine front to the public (Groves 2001). Activists recognized that maleness brings with it a sense of credibility, legitimacy, and authority which is believed to more effectively solicit attention to the plight of Nonhuman Animals.

Vegan feminists of this era, too, hoped to maintain patriarchal critiques while adopting patriarchal values. Feminists for Animal Rights (FAR), the preeminent force in second wave vegan feminism, for instance, maintained its grassroots structure throughout its lifetime, but its unmet goal for nonprofitization was a consistent worry (Cite Author's Work Here 2019). As the Nonhuman Animal rights movement professionalized in the 1990s, it altered the political ecosystem. Grassroots, chapter-based collectives that operated along a more feminist organizational structure and either refused to or were unable to adapt to the new standard were starved out of existence. This appears to have been the case with FAR, which ceased operations on the eve of its final and most concentrated push for professionalization after having finally achieved charitable nonprofit status. The dozens of other feminist collectives (remembered only in their sporadic mention in FAR newsletter archives) also failed to professionalize or survive the second wave. In retrospect, it was clearly necessary to play by men's rules of conduct in the public sphere in order to play at all.

Today's movement remains largely professionalized, but the $21^{\text {st }}$ century format is structurally distinct. As was the case with other movements, vegan activism moved online. Activists now employ social media for organizing protests and disseminating information, privileges that elitecontrolled institutional channels had otherwise blocked. Where once a professional, bureaucratic 
nonprofit had been a requirement for successful activism, now effective online engagement has become requisite. This digital shift has an especially potent impact on vegan activism given the inherent distances between vegan activists in a deeply speciesist world. My research into the $21^{\text {st }}$ century vegan community finds that most activists come to veganism of their own volition and cognitive deliberation, and only to a lesser extent do they emerge through personal connections to individual vegans, activists, or collectives (Cite Author's Work Here 2017). Consequently, the internet has become the movement's most important organizer. Online activism increases the reach of a movement's message (Earl and Schussman 2003) and can overcome media bias in protest coverage (Almeida and Lichbach 2003).

This third wave of activism is also global. Advancements in technology have surpassed the barriers of long-distance phone charges, slow postal mail, and miles of physical distance. Today's activists are working in a terrain that is deeper, more rapidly functioning, and, in many ways, more personal. For vegan feminists, the intimacy of online engagement and the influx of new ideas and cultures created renewed relevancy of feminist thought. Emboldened by women's liberation and sharpened by ecofeminist scholarship, $20^{\text {th }}$ century vegan feminists had developed a strong analysis of intersectional oppression. This privileged third wave vegan feminists such as myself with an existent platform of knowledge to apply and extend. The challenge was how to make relevant the wisdom learned, developed, and, frankly, forgotten, since the movement had professionalized and moved online to a new generation's fingertips.

For some time, Name of Organization (NO) was a relatively lone feminist voice in the movement in this regard. NO was largely a project of necessity and personal validation. When I began blogging about contemporary problems of sexist movement culture and the horrible pushback I had experienced from colleagues and organizations I trusted and admired, there were no other vegan feminist blogs, podcasts, or Youtube channels to which I could turn. Although I felt alone, I knew that I was not. Indeed, the 2010s marked a new feminist turn in the vegan community. Gaarder's (2011) survey of women in the Nonhuman Animal rights movement documented underlying misogyny within activist circles, but it was a problem that remained uncritiqued since Marti Kheel and her comrades ceased typing handmade FAR newsletters a decade earlier. Dr. Breeze Harper was perhaps the leader in tackling intramovement violence in third wave activism, evidenced in her 2010 edited book Sistah Vegan and her 2011 open-access article, "Race as a 'Feeble' Matter," both of which balance out a large catalog of blog essays on this topic of intersectional failure in vegan advocacy. Outside of Harper's blogging, however, little vegan feminist research had escaped the ivory tower of academia to permeate the activist imagination.

For these reasons, I would not be so brazen as to suggest that Name of Organization was the reason for the intersectional shift. I can, however, venture to guess that it was an accelerant. This essay will outline the emergence of my work through NO, what movement conditions necessitated its formation, and the general resistance that vegan feminist campaigning has faced. In doing so, I argue that $21^{\text {st }}$ century vegan feminism is uniquely characterized by new channels of online communication and the threat of neoliberalism. I suggest that online communication provides a rare platform for marginalized groups such as women, disabled persons, and people of color to disseminate their critical theory, but this privilege is counterbalanced by the negative 
influence of movement professionalization which feeds on sexism, racism, and even, as I will argue, speciesism. However, I also suggest that professionalization brings with it a sense of continuity and security, the lack of which undermines the stability of decentralized feminist advocacy. Feminist advocacy contends with its own internal difficulties in maintaining a healthy and viable activist community.

\section{Building a Network after The Sexual Politics of Meat}

When I began teaching gender studies in 2012, I quickly came to realize the vital importance of feminist theory to the anti-speciesist cause. In fact, it became a turning point in my career. As feminist research was coming to inform my activism, it became apparent that my vegan activist community was generally ignorant to and sometimes even adverse to feminism. This revelation was both shocking and unsettling to me. I think it is fair to say that Carol Adams' The Sexual Politics of Meat (2000) (vegan feminism's magnum opus) had successfully seeped into the movement culture in the decades since its initial release, but Adams was and, in many ways still is, the movement's token feminist. The popularity of The Sexual Politics of Meat has allowed activists to superficially align with anti-sexist values without having to do the difficult task of self-evaluation or community accountability. This allowance could owe to the limited focus of Adams' catalog which pertains to wider cultural misogyny and offers precious little critique of how that misogyny persists within vegan circles. Placated by their familiarity with Adams' theory, most activists have failed to delve deeper into the critical work of other feminist theorists, a practice that might encourage serious attention to problematic movement structures. Feminist works of this kind which "air the dirty laundry" of the movement are largely ignored, suppressed, or shamed into obscurity. Activists, urged by the enormity of violence facing Nonhuman Animals and swayed by victim-blaming mentalities that pit women as conniving, are more likely to disparage feminist writers as selfish, gossiping, disgruntled women who should suck it up. After all, the movement has The Sexual Politics of Meat, so it cannot be sexist.

This post-feminist ideology is not unique to vegan spaces but challenges mainstream feminists as well (McRobbie 2005). With all the glitz and glamor of consumer choice foisted on modern women, feminism in the $21^{\text {st }}$ century simply reads as redundant and no longer relevant. It is a cruel twist that the lessons of second wave feminism have educated folks such that they believe themselves "woke" and no longer in need of feminist teachings even though gender inequality remains painstakingly rife. In the Nonhuman Animal rights movement, this assuredness is probably complicated by the misleadingly obvious fact that most activists are female-identified. How can a movement of women be sexist? Well, I would argue that it is because the movement has a female majority that it becomes vulnerable to sexism. Femininity is interpreted as a vulnerability, thereby encouraging activists to align with patriarchy in order to resonate. A female majority also invites predatory men who can enjoy a glass escalator to the most powerful and celebrated positions and easy pickings from an especially caring and trusting female constituency made doubly vulnerable by their empathetic vegan leanings and female socialization.

Since 2012, I have committed myself to exploring and challenging this anti-feminist resistance in the post-Sexual Politics of Meat age of third wave Nonhuman Animal rights activism. While the 
movement is composed primarily of women, it is still largely a reflection of the patriarchal structures that characterize broader society. As evidenced in an infographic I created for Name of Organization in 2016 (fig. 1), two-thirds of the Animal Rights Hall of Fame inductees are male and only $38 \%$ of the most influential charities are led by women. As just one example of how sexism manifests within these patriarchal arrangements, the most high-ranking women of the Humane Society of the United States were only making 54 cents to a man's dollar. As would later emerge, these women were also dealing with systemic sexual harassment by male superiors (Bosman, Stevens, and Bromwich 2018).

Despite these glaring inequities, women, people of color, and other vulnerable groups have been victimized, alienated, and silenced in advocacy efforts on behalf of other animals. Prior to Name of Organization's launch in July 2013, there had not been, to my knowledge, any organized effort to specifically resist vegan sexism since the efforts of Feminists for Animal Rights which had folded at the turn of the $21^{\text {st }}$ century. Activists lost FAR at the critical point in which the movement was entering a third wave characterized by online advocacy and neoliberal bureaucratization of formal groups. The modern movement required modern measures of feminist critique, but the "old guard" of vegan feminism was largely unplugged and either unable or unwilling to enter fields of online discourse where so much movement-making now takes place. Through my internet activism, I knew of several like-minded young women who were full of innovative new ideas about intersectional activism, but our knowledge was wasted in the short-lived and quickly buried comments sections of various online channels. I founded the website and online advocacy organization Name of Organization to manifest this lacking platform. Its mission was (and is) to eradicate oppression from the Nonhuman Animal rights movement and improve inclusiveness through dialogue and educational resources. We were in our 20s, plugged in, and eager to transform the movement with the newfound power of blogging.

Our cyber strategy of social media education and critique may have been innovative in the vegan community, but we were only employing advocacy strategies that had been in successful operation in the larger social justice realm. Indeed, the internet was dramatically altering collective action everywhere (Castells 2012). It impacted who could participate, how they participated, and the extent of their reach. The neighboring feminist movement, for instance, had embraced online activism as an accessible means of bringing a platform to traditionally excluded participants (Thelandersson 2014). Second wave feminists were limited by the cost of photocopies and stamps, but third wavers thrived on clicks, likes, and shares. Online channels provide an accessible, low cost means to form communities, construct social identities, and "redefine social realities" (Dixon 2014, 39). These possibilities are tantalizing in a movement landscape that has largely professionalized, and, subsequently, had adopted a masculinized structure that privileges the interests of elites to the effect of alienating most participants from decision-making. Young activists no longer needed to wade through tomes of archaic feminist literature to learn basic theory, an endeavor generally available only to privileged college students and professors. They could now access blogs that distilled this information at the click of a mouse. Furthermore, these activists no longer needed to assimilate into formalized movement channels in order to contribute to the dialogue. They could create blogs themselves. 
Knowledge was democratizing. Internet technology, in other words, was poised to disrupt movement hegemony and provided a rare channel of dissemination for radical ideas.

\section{Understanding Vegan Sexism}

In light of these new possibilities, perhaps the most fundamental task at hand for vegan feminists is not to educate the public on the intersection of sexism and speciesism, but to first educate the movement, the Animals' ambassador. Patriarchy is a male-dominated social structure that necessitates the oppression of feminized groups. As a microcosm of larger society, the Nonhuman Animal rights movement demonstrates many forms of sexism that are designed to protect male power and entrench female powerlessness. The disparities discussed thus far and to be discussed below are typical and predictable patriarchal symptoms, which, left ignored and unattended, are not likely to self-correct. The following survey of institutionalized sexism was originally published on the NO website and outlines how macrolevel societal sexism is linked to the microlevel vis-à-vis vegan organizations and interpersonal relationships.

\section{Gender Capital}

As of 2016, only $22.8 \%$ of national parliamentarians were women, and, as of 2017, only 11 women serve as head of state (UN Women 2018). More than half of the world's population is female, but women hold only a fifth of the world's legislative seats. Why should vegans care? This leadership distortion extends into the Nonhuman Animal rights movement. Approximately four out of five activists are women (Gaarder 2011), but they represent much fewer positions of leadership (fig. 1). When positions of power and decision-making are granted primarily to men, it can reasonably be expected that men will, whether intentionally or not, privilege their own interests. Women require equal participation in political processes to ensure that their needs are being met and that women's interests are being represented appropriately. Sexism invites critics to dismiss women's desire for political gender parity as a selfish pursuit (a cardinal sin for women) given the magnitude of Nonhuman Animal suffering, but effective activism for other animals requires effective organization. If women are excluded, this is not indicative of effective organizational structure. It is instead indicative of a movement that is unable to employ the most basic principles of social equality within its own ranks.

Vegan feminism argues that patriarchal oppression provides the logic to speciesism such that a failure to acknowledge women's oppression is symptomatic of a movement that has a limited grasp on species oppression. It also suggests to me an underlying resistance to establishing more equitable social arrangements despite its posturing to the contrary. This is understandable. Sociologists recognize that those who have power rally to protect and hoard that power via the construction of prohibitive institutional barriers and ideological norms (Adamson 2014; Bourdieu 1977).

Beyond politics, the gender disparity is also evidenced in the corporate world. As of this writing, less than 5\% of CEOs leading Fortune 500 companies are women (Fortune 2018). Women are systematically and actively blocked from accessing powerful positions, often due to exclusion from important networks and stereotypes about their suitability for leadership (Barnett and Rivers 2004). Again, vegans have reason to care because the absence of women in powerful positions is reflected in the Nonhuman Animal rights movement. This, in turn, suggests a general devaluation of women's ability and input. In advocacy efforts, women are far more likely to 
make up the "rank and file," working hard behind the scenes to accomplish the necessary, but largely uncelebrated, mundane tasks of social movement maintenance. Men write the theory, lead the protests, and lecture on podcasts, while women "make the coffee" so to speak. Although I have argued that the Nonhuman Animal rights movement is particularly vulnerable to regressive gender norms, it is also true that many social movements grapple with sexism in thought and practice (Lawson and Barton 1980). For instance, the Civil Rights movement relied heavily on the community organizing and microlevel leadership of women, but high-profile positions were reserved predominantly for men (Robnett 1996). Although some might suggest that this gender segregation is functional in its division of labor and task-sharing, I would counter that it constitutes a terrible squandering of a potentially powerful demographic by failing to channel the creativity and capabilities of thousands of women.

\section{Gendered Violence}

Most insidiously, the systematic exclusion of women is directly related to their social devaluing and susceptibility to violence. At least one in three women will be raped, beaten, or otherwise abused by a man or men at least once in her lifetime (United Nations 2008). This number is much higher for college students (who constitute the bulk of social movement participation) and would be higher still except that many women do not feel safe reporting assault or, due to patriarchal conditioning, do not recognize their assault as such. Vegans have reason to care about this gendered terrorism because men's violence against women flourishes in the Nonhuman Animal rights movement.

In my own activist career, I have personally anguished through countless experiences with antispeciesist men's misogynistic bullying, stalking, sexual harassment, and intimidation. Many men pursued their attacks on me for years with horrifying determination, goaded by my feminist resistance and encouraged by the movement's culture of silence and collusion. I felt at times that I was enduring a movement-wide gaslighting campaign. I blogged about my experiences only to endure torrents of angry comments, anonymously delivered abusive emails, and overwhelming silence or victim-blaming comments from second wave feminists and organizational leaders of charities both professionalized and grassroots. As a professor of gender studies, I recognize this behavior as endemic to a misogynistic culture that protects status quo power relations by invisibilizing, ignoring, or demonizing survivors, but that did not make it any less disturbing.

It is most ironic that feminists are routinely dismissed as attention-seekers, when, in reality, our daring to put words to the injustices we experience quickly shrinks the community spaces available to us. Male colleagues, unwilling to acknowledge their male privilege and feeling "oppressed" by my feminist politics, turned on me. Leading professors and theorists in the movement who had propped up their personal brand though softcore, pop feminism, labeled me a bigot, refused to write me letters of recommendation, sided with avowed sexists, or awkwardly ignored my direct pleas for help. Experiencing gendered abuse can be extremely isolating for these reasons. Targeted women are left to question their own sense of reality and morality, while aggressors are not held accountable. The sanctified suffering of Nonhuman Animals is given precedence, while women, historically expected to put the needs of others before their own, are made to feel selfish and traitorous. Gender abuse characteristically makes victims feel alone, obscuring the fact that it is collectively experienced. 
As a sociologist, I understood that a collective consciousness is transformative. When I made my stories public, acquaintances shared their own stories with me privately. Some even published them publicly on NO. NO helped to resist feelings of isolation, and I hoped it could demonstrate that the horrible personal tragedies dotting the movement were actually evidence of a systemic problem. In the years since NO's launch, my work has come to recognize that sexual violence undergirds the oppression of women and other animals, and, more specifically, that the Nonhuman Animal rights movement regularly contributes to rape culture in its bid for resonance. Rape culture refers to a social landscape in which rape and violence against women are trivialized, normalized, and even condoned (Harding 2015). This culture does not stop short at the borders of the vegan community.

It seems that vegan women are offered one of two options. They may do the unglorified drudgery and invisible labor of collective organization behind the scenes or, if they meet the racial and corporal standards of beauty, they may get naked "for the cause" in "I'd Rather Go Naked" campaigning popularized by People for the Ethical Treatment of Animals (PETA). Although most vegan women may choose (or be defaulted into) the nonsexualized role, the fact that "sex object" is a role expectation for vegan women and not men essentially secures women's vulnerable, second class status at the institutional level. Sexualizing female activism could be a strategic mistake however, given that the sexual objectification of women is directly responsible for women's low self-esteem, low self-efficacy, self-objectification, and even eating disorders (Szymanski, Moffitt, and Carr 2011). Downtrodden and distracted women are not likely to be an effective force for change. Sexual objectification is also directly related to prevailing misogyny and violence against women. Most assuredly, sexual objectification is a fundamental component to rape culture.

Turning persons into things is a necessary precursor for enacting violence on those "things." Sometimes the Nonhuman Animal rights movement explicitly pulls on narratives of victimblaming when sexually objectifying female activists. For instance, LUSH, a luxury soap company that also brands itself a force against speciesism (despite the fact that most of its products contain Nonhuman Animals' milk, eggs, oils, and honey), once hosted a ten-hour street spectacle featuring an animalized woman costumed to appear naked who was tortured by a man in a lab coat. Responding to criticism, LUSH's spokesperson declared, ${ }^{4}$ in so many words, that the publicity stunt intentionally chose to target women in order to teach women (who purchase tested cosmetics) a lesson (Cite Author's Work Here 2016a). Most nonvegan products are sold to men, however, suggesting that the campaign was instead relying on tried-and-tested misogyny to grab attention. As this example demonstrates, Nonhuman Animal rights campaigns use women's bodies as sites of sexualized violence to register with a woman-hating public socialized by a pornographic, hyper-sexualized media (Cite Author's Work Here 2015). Violence against women-a lived reality for millions-is made sexy in campaign after campaign. With women's bodies are used as bait so as to invite predation (Cite Author's Work Here 2016b), it is unclear

\footnotetext{
${ }^{4}$ Spokesperson Tasmin Omond (2012) states:

We felt it was important, strong, well and thoroughly considered that the test subject was a woman. This is important within the context of Lush's wider Fighting Animal Testing campaign, which challenges consumers of cosmetics to feel, to think and to demand that the cosmetics industry is animal cruelty free. [ . .. ] It would have been disingenuous at best to have pretended that a male subject could represent such systemic abuse.
} 
how a body of new participants swayed by these oppressive scripts will be equipped to take speciesism seriously and effectively combat it.

Rape and sexual assault in activist circles may fail to solicit concern given the numbing effect of rape culture, but sexual violence is not unrelated to battering and homicide. Might this connection warrant serious attention? In the United States, the Center for Disease Control (2015) reports that one of the leading causes of death for girls and women is men's violence. In 2015 alone, over 1,600 American women were killed by men (Violence Policy Center 2017). To put this into perspective, approximately 3,000 persons were killed during the attack on New York's World Trade Center, and following that attack, the entire infrastructure of American international relations and global air travel were transformed. Yet, women are raped, terrorized, and killed by the thousands each and every year without inspiring meaningful state action or intervention. Given the Nonhuman Animal rights movement's flippant use of misogynistic imagery in its campaigning, these levels of violence do not seem to alarm vegans either.

\section{Selling Animal Rape}

Ironically, the Nonhuman Animal rights movement's ignorance to sexism and rape culture manifests in its treatment of Nonhuman Animals as well. Indeed, due to the intersectional nature of sexism and speciesism, sexism - which entails the exploitation and derogation of feminized bodies - encourages activists to treat animals as women, just as speciesism - which entails the exploitation and derogation of animalized bodies - encourages activists to treat women as irrational, bodied, inferior, animal-like beings. This intersectional logic of oppression means that Nonhuman Animals, thus feminized, serve as a pool of female labor to be tapped for movement ends just as vegan women are. Specifically, this exploitation transpires in the form of pornography. Pornography, like prostitution, relies on the sale of women's bodies in return for various resources to the organization's benefit. It is an institution which is highly correlated with women's subjugation (MacKinnon 1989). Perhaps the only meaningful distinction between prostitution and pornography (both institutions commodify the female body for the profit of predominantly male owners) is that pornography is recorded in picture, be it photograph or video, creating an easily reproduced product with a greater market reach. The pornification of female activists is well documented in anti-speciesist spaces (Cudworth 2011; Deckha 2008; Gaarder 2011; Cite Author's Work Here 2015), but less discussed in the research is the pornification of nonhuman females.

Although most vegans come to the movement of their own volition, the Nonhuman Animal rights movement relies on two primary tactics of recruitment, the first being networks (familiarity with and proximity to other activists), and, failing that, the use of morally shocking imagery (Jasper and Poulsen 1995; Cite Author's Work Here 2013). A wide variety of revolting images of Nonhuman Animal suffering are utilized by activists, often with the intent of creating intense feelings of disgust, empathy, or outrage. These reactions are hoped to "shock" the viewer out of complacency and into action. Common themes include victims of vivisection riddled with research instruments, food animals in the slaughterhouse, or pitiful castaways huddling in cages awaiting "euthanasia." These images are inherently feminized, as they objectify a subjugated group for the human gaze. However, many images take this even further and specifically feature the sexual violation of female animals (fig. 2). 
The purpose of pornography is to titillate via the sexual degradation and humiliation of an oppressed body (Dworkin 1981). Those who consume pornography are consuming it specifically to "get off," so to speak, on the demonstrated powerlessness of otherized bodies. The relationship between the viewer and the viewed is one that reproduces and reinforces a hierarchy of domination. Pornography users also report experiencing a "tolerance," meaning that increasingly degrading and shocking imagery is needed for them to register and respond. The pornography industry is happy to serve that need by producing increasingly disturbing media (Jensen 2007). In anti-speciesist mobilization efforts, another unfortunate intersection of sexism and speciesism thus surfaces through the sensationalizing of anthroparchal ${ }^{5}$ rape which, I argue, not only derives from rape culture, but also serves to aggravate rape culture. As animal law scholar Lee Hall (2010) insists, these images revictimize Nonhuman Animals. The depiction of objectified victims in pictures does not encourage the human subject to respect their personhood. Rather, it reinforces their subordinate status.

MacKinnon (1989) suggests that survivor's stories become an "oral pornography," with narratives soliciting a sexualized or victim-blaming response, which actually confirm the legitimacy of women's subjugation to the audience. For Nonhuman Animals prostituted in pictures, empathy, if extracted at all from the viewing experience, exists within the context of human superiority thus created in this relationship between the viewer and the viewed. Furthermore, there is no possibility of consent from these depicted Nonhuman Animals. Nonhumans, distant and frequently dead, do not have the capacity to allow for their traumatic experiences to be publicly displayed and exploited for the movement. A case can be made that using an Animal's image without consent is in the interest of the greater good, but this does not negate the fact that the consent of Nonhuman Animals is treated as overridable.

The sexual violence inflicted on female nonhumans is eternally documented and replayed in activist pornography, but the human survivors of sexual violence made witness to these images are revictimized as well. True, rape is a trans-species experience, and rape is systematically utilized by a capitalist society to control the feminized, but the context in which the institution of rape is engaged by activists is problematic. Morally shocking anti-speciesist images are designed to trigger; they are constructed in such a way as to set off a complex and powerful emotional response in the viewer's psyche. As with any pornography, they are intended to emotionally arouse. I posit that tactics that intend to trigger women's collective memory with male violence rely on scripts of misogyny. In this way, women are prostituted once again by vegan activism as their bodily and psychological violation is capitalized upon for the benefit of others without their consent. Women, historically stereotyped as giving, selfless, and docile, are not expected to have a problem with the movement's potentially traumatic imposition.

I challenge that the movement's systematic exploitation of female suffering and disregard for consent is not likely to be successful in dismantling oppression. Indeed, these tactics only facilitate it. Recall, images of animals suffering are intentionally selected with the expectation of rousing a reaction, and, in the corporatized movement space, that reaction is generally hoped to be a monetary one (Cite Author's Work Here 2015). But this approach is surely alienating to women in a society where rape, assault, and murder at the hands of men or the state, as was previously outlined, are standard practice. In addition to alienating women in the broader public,

\footnotetext{
${ }^{5}$ This is a term used by Cudworth (2011) in reference to human supremacy.
} 
these tactics also alienate women in the ranks as well. With remarkable cruelty, the intersections of human and nonhuman violation are juxtaposed in such a way as to create barricades instead of connections. The Nonhuman Animal rights movement's misogynistic repertoire becomes one more means of alienating women from anti-speciesist work. It becomes one more means of solidifying male rule over advocacy spaces. Scripts of misogyny keep women in a constant state of not-belonging, victimhood, and hurt. Adams suggests that pornography is inherently speciesist because "[...] women's orifices are a part of the accessible environment available to men" (1996, 177). That is, the same logic that entitles those in power to exploit nature is the same logic that allows those in power to exploit women. I suggest that this domination logic persists when human activists enact their entitlement to exploit the devaluation of Nonhuman Animals.

While this trend began to emerge in second wave advocacy materials given its heavy reliance on shocking visuals, I would argue that it is amplified in the third wave. The exploitation of women's bodies in the movement is not simply a result of patriarchy; it is also a result of capitalist pressures. As social movement organizations struggle to exist, they often turn to the nonprofit model. The social movement arena is crowded and competitive, and so the exploitation of women is used strategically. Although much of this activity is condoned as a matter of personal choice made by individual participants (Mirk 2015), what little is acknowledged as exploitative and nonconsensual (audiences and Nonhuman Animals cannot consent) is frequently dismissed. Again, some activists may insist that consent should be waived if exploiting this female suffering is believed to be in the best interest of other animals or the "common good." This paternalistic position, however, is itself oppressive as activists and organizations thus position themselves as the guardians and custodians of infantilized women and other animals.

Anti-speciesist activists are increasingly coming to recognize that slavery and Holocaust analogies are problematic tactics for "selling" Nonhuman Animal rights to a public still smarting from the ongoing trauma of institutionalized racism and ethnocentrism (Socha 2013). However, the frequently employed analogy of rape (particularly in reference to dairy production) goes practically unexamined by movement actors. Women are sometimes depicted as the recipients of physical and sexual assault to make a point about the experiences of cows. ${ }^{6}$ I find it curious that, when female audiences are targeted, there seems to be little objection even though tactics of this kind represent a very similar act of violence to that of slavery and Holocaust analogies.

The exception made for misogynistic scripts in the Nonhuman Animal rights marketplace is an intriguing one, one that speaks clearly to the woman-hating nature of Western culture. One of the more frequent rationales employed to justify the exploitation of female bodies and trauma in the service of social justice is the need to expose the "truth" of speciesist industries. But the demonstration of "truth" is constrained by a number of rarely-crossed boundaries in the activist repertoire. Again, race and ethnicity analogies, while admittedly still employed by some in the movement, are coming under scrutiny from a number of movement pundits. Pedophilia, however, is even less frequently utilized. In fact, no campaign that draws on the sexual abuse of human children to make an argument against speciesism comes to my mind at the time of this writing. This is a strange omission if activists are simply interested in exposing the "truth" of species-based violence because the cows in the dairy industry are still babies and children

\footnotetext{
${ }^{6}$ See, for instance, the street protests of global organization 269life (2013) which are hosted on Youtube at https://www.youtube.com/user/269lifecom/videos.
} 
themselves when they are hoisted onto "artificial insemination breeding chutes" and vaginally or anally penetrated by male farmers who inspect or alter their reproductive organs. Pedophilia analogies might actually be more accurate than those that draw on violence against adult women. This recognition of boundaries for groups other than women suggests that singling out the female experience is intentional and formulaic. The "truth" here is carefully framed, not objectively reported. In a woman-hating society, presumably only misogynistic scripts will sell. Misogyny is the only language the public is expected to understand and feel comfortable consuming. Adams adds that analogies of this kind assume the "reducibility" of suffering and objectify it. Instead, she suggests a retreat from anthropocentric metaphors: "[...] why not say animal suffering in their body is theirs?" $(1996,184)$.

Misogynistic imagery is intended to titillate the audience to the point of purchase. Pornography is deliberately designed and delivered to stimulate the viewer to a point of emotional excitement and physical reaction. In the realm of online pornography, where millions upon millions of websites offer photographs and short video clips for free, the creators hope to work up the audience to such a point where they will be more willing to offer their credit card information for paid content (Dines 2010). The institution of pornography specializes in consumer manipulation, and pornography is manufactured at a cost to vulnerable female bodies with the intention of turning a profit for predominantly male capitalists. When social movements use graphic images of female nonhumans being violated (sexually or otherwise) by those in power with the human/male gaze in mind and with hopes of extracting capital from the viewer (since most depictions of Animal suffering are associated with nonprofit campaigning), this system can only be understood as pornographic. This is not the type of pornography that is likely to empower Nonhuman Animals. It is more likely to reinforce their lower status.

The exploitation of feminized Nonhuman Animals in morally shocking imagery also acts as a cheap plot device in the narrative of the benevolent human savior. Demeaning images are heavily shared within the activist community as a means of exciting rage and desire for vengeance. Crude images of Nonhuman Animals being kicked, beaten, sexually assaulted, dismembered, and murdered in the most horrific ways are swapped among (or forced upon) activists with encouragements to feel anger and an intense desire to "do something" (Jacobsson, Lindblom, and Jacobsson 2013). Ecofeminist Marti Kheel wrote at length about the dangers of this "savior complex" in anti-speciesist spaces throughout her career. Instead of examining the root cause of exploitation, activists and theorists look to nonhuman pornography to feed their inner vigilante. The vegan feminist perspective, however, sees social change grounded in respect for the exploited and peaceful, non-violent education for the exploiters. Kheel (1993) explains:

Whereas nature ethicists have tended to concentrate on "rescuing" the "damsel in distress," ecofeminists have been more likely to ask how and why the "damsel" arrived at her present plight. [ . . . The natural world will be "saved" not by the sword of ethical theory, but rather through a transformed consciousness toward all of life.

"Victims in pictures," as Hall (2010) describes them, become further oppressed when their experiences are shared in a manner that does not respect their personhood. In doing so, they simply become objectified in the storyline of activism. Given that the Nonhuman Animal rights movement already operates according to patriarchal norms and generally celebrates violent direct 
action (Hall 2006), it seems quite fitting that Nonhuman Animals are presented as victims. This victimhood presents androcentric activism the justification needed to engage further in patriarchal violence. While violent activism is done in the name of social justice, the "might makes right" logic that supports this approach is firmly situated within an ideology of patriarchy.

\section{Measuring Success}

I have argued that the third wave of anti-speciesist activism is characterized by democratic online access and widespread nonprofit professionalization. These structural shifts had major consequences for vegan feminism. Internet advocacy offers a powerful platform for the heretofore overlooked feminist critique, but this advantage is countered by the deeply patriarchal professional model and its capitalist requirements for competitive campaigning that inevitably exploit feminized labor, both human and nonhuman. Yet, this professionalization could intriguingly offer another window of opportunity for vegan feminism since it also requires a deradicalization that invites organizations to dabble with diversity.

With any social movement, it is difficult to determine at what point "success" has been achieved because movements are generally quite multi-faceted and adaptive. Influence can sometimes be interpreted through cultural impacts, policy changes, and institutional restructuring, but, it is usually the case that only a few elements of a movement's goals manifest in a social structure. Social movement goals generally only achieve assimilation in a heavily compromised form unless the goal is extremely single-issue. Queer liberation, for instance, settled into the not-soqueer fight for marriage equality (Healy, Sheehan, and Whelan 2015). To succeed, the movement funneled a huge array of grievances into a single, more achievable goal that strategically spotlighted middle-class, monogamous white males. Vegan feminists such as Aph and Syl Ko (2017) have been cynical of diversity initiatives in the Nonhuman Animal rights movement for this reason. Vegan feminist demands for diversity have been somewhat addressed by professionalized anti-speciesist organizations, but mostly in a form that is very limited in its representativeness of actual diversity in the community and constituency. Ko and Ko observe that vegan diversity quotas are generally qualified by idealized expectations and respectability politics.

Post-feminist ideology permits this faux diversity to pass as true progress, but this "progress" is rendered even more vacuous by its marketability. In an analysis of over forty years of movement literature following Western Nonhuman Animal rights mobilization through the peak of late $20^{\text {th }}$ century second wave activism to the era of professionalization in the third wave, I have uncovered that the increase in vegan intersectionality rhetoric generally coincides with movement deradicalization. Nick Pendergrast's (2014) doctoral research also supports this finding. Anti-speciesism claimsmaking is, for the most part, rather radical, and movement organizations, having adopted the nonprofit model, become beholden to bureaucratic inertia and the constant need for funds. I suspect that intersectionality rhetoric shifts attention from the radical notion that animals are persons by centering humans.

Diversity is subsequently employed to the professionalized organization's advantage in two ways. First, social movement organizations can appeal to post-feminist myths that sexism and other forms of human oppression are no longer relevant. Second, social movement organizations 
can decenter contentious Nonhuman Animal liberation. In both cases, true diversity is thwarted in favor of a veneer of carefully controlled inclusivity. This maneuvering is necessary given the threat that feminism and veganism pose to existing power structures. Despite the good intentions of many charity workers and volunteers, the nonprofit model has been criticized as a tool of the state, one nurtured since the late $20^{\text {th }}$ century to temper rebellion, squash radical collectives, increase activist transparency, and provide affordable social services (Smith 2007).

Given the potent influence of professionalization on the trajectory of Western charities, it is difficult to declare with any certainty that the early efforts of NO and other likeminded projects have manifested the movement's new interest in intersectionality. I am wary of professionalized nonprofits such as PETA celebrating women's empowerment and Farm Animal Rights Movement's (FARM) inclusion of feminist speakers at its annual conference given their general commitment to patriarchal movement structures and financial dependence on industry and state elites. Yet, the explosion in grassroots vegan feminist projects like A Privileged Vegan, Black Vegans Rock, Collectively Free, Project Intersect, Vegan Princess Warriors Attack, and Vegan Vanguard suggests that a space has been claimed for critical thinking.

Further evidence to the effectiveness of a critical vegan feminist message is the development of countermovement efforts, as evidenced in the fan base of Gary Yoroufsky, Gary Francione, 269life, and other male-dominated entities which fiercely resist feminist critique. Vegan feminists may easily find themselves downtrodden by the retaliatory misogynistic abuse emanating from these spaces, but, as a scholar of social movements, I recognize that this contentious resistance is likely a sign of success. Countermovements cannot develop without the presence of a viable threat, as countermovements exist only to protect elite interests and the status quo (Meyer and Staggenborg 1996). Countermovement activity is thus powerful evidence that vegan feminist critique is registering. Response, even if negative, is the sincerest form of flattery in the crowded social movement space that so often invisibilizes the contributions of women. For that matter, this movement-countermovement dialectic can encourage ideological development and tactical refinement. I certainly would not have sharpened my feminist framework to such an extent without the regular pushback.

\section{Coping with the Pushback}

That said, social movement research warns that countermovement activism can easily escalate into violence when elites whose privilege is challenged reach a certain point of frustration (Mottl 1980). Given the general societal danger facing women, the post-feminist mentality of vegan communities, and the documented threats and harms already beleaguering women in the feminist movement, vegan activists have every reason to take seriously the risks involved in vegan feminist agitation. It is my observation that most activists in the Nonhuman Animal rights movement have adopted a do-gooder, hyper-moral identity to differentiate themselves as people who care about animals, an identity that, ironically, impedes their ability to acknowledge contrary behavior in the ranks. This is compounded by the everyday ideological barriers of sexism. In The Revolution Starts at Home (Chen, Dulani, and Piepzna-Samarasinha 2011), social justice activists and collectives working in liberation efforts for women, children, racial and ethnic minorities, trans and queer persons, and immigrants have identified that intramovement 
violence can be just as unsettling as the structural violence they originally organized to resist, if not more so. It can also be just as tricky to dismantle, especially if plans for this dismantlement intend to eschew traditional channels of state control and oppression such as the criminal justice system.

The load is a heavy one. As I write this piece, I recognize that Name of Organization, like many grassroots collectives, has entered a period of abeyance and may very well cease to operate. Unprofessionalized radical groups like NO may have the luxury of speaking truth, but this comes at a cost of resources like funding and powerful networks. Taking a critical stance entails an element of precariousness. Eventually, the steam runs out, the compassion fatigue sets in, or the trolls wear us down. For me, it was not long into my stint as a non-tenure track lecturer at a small liberal arts college before I felt the disarming pull of heavy teaching loads and tenuous three-year contracts. Like the large charities I had long criticized for failing to maintain a radical position, I, too, felt the need to protect my paycheck in a depressed economy. I come from poverty, am unmarried, and have no safety net, so it was not difficult for university employment to professionalize me. This has entailed a chilling of my activism and a pandering of my message.

After one high profile vegan misogynist who worked at a neighboring institution began to escalate his abuse, I found myself in the dean's office discussing measures of personal and professional protection. My dean was familiar with this abusive behavior in academia and was very supportive of me, but I still felt embarrassed and unprofessional for having to address it in the first place. As a young woman who lives alone, I feared for my safety. I knew this man watched every move I made online; was he also watching me offline? I knew he had destroyed the reputations of other female junior scholars in the field. I was now in his crosshairs; could my career withstand his attack in an industry that already devalued and demeaned women? I developed eczema. I cried a lot. I worried a lot more. The terrifying recognition that vegan men's countermovement activity was beginning to threaten my career and mental health forced a reckoning. I began to reinvest my efforts away from online activism to professional pursuits. Teaching four to five introductory classes every semester distracted me. Eventually, I had no more time for blogging. I convinced myself that teaching and publishing were equally valid means of advocating for Nonhuman Animals.

In a lot of ways, cooling my online activism meant disengaging with the vegan community. This split was not entirely one-sided. Another consequence of radical feminist critique in a maledominated space is the general discouragement that women experience. This is precipitated by a lack of solidarity and support, especially from older, better-established activists who are in a position to ease young women's burden through their greater credibility and richer networks. I have always found this failed sisterhood an especially stinging quality of a professionalized movement culture that seems to be determined to keep up appearances no matter the cost. It smarts all the more when diversity rhetoric plasters conference lineups, annual reports, book jackets, and mission statements while women continue to suffer in isolation, unbelieved, tonepoliced, or victim-blamed. 


\section{Conclusion}

Gender equality matters in the vegan movement for three reasons. First, social movement research indicates that a diversity of representatives will be more likely to resonate with a diverse audience (Reger 2002; Staggenborg 2010). A diverse audience is needed for social change. Second, diversity in leadership provides role models who attract and nurture a diverse activist pool. Social psychological research supports that marginalized people find a sense of agency and belonging when they see people like themselves doing important work (Beaman et al. 2012). Third, a white-centric and male-centric movement invariably relies on the very same hierarchies of power that facilitate speciesism. The sexualizing of violence against women masked as a metaphor for speciesism and the selling of Nonhuman Animal rape in pornographically-charged graphic imagery both demonstrate some of the tactical concerns that emerge from a movement exhibiting intersectional failure. Vegan feminism has advanced a campaign to challenge limiting ideologies of privilege and power by suggesting that women and other marginalized groups in the Nonhuman Animal rights movement be given platform and mutual respect.

The internet opens up to activists an enormous, global community and valuable networks through which to disseminate radical ideas in the service of a more just society. Yet, vegan feminists such as myself who espouse unpopular feminist opinions in a single-issue-minded social movement environment may still find themselves alienated since a radical vegan feminist message can run contrary to the political logic of the nonprofit model. It remains to be seen if the vegan feminist flank can overcome the structural barriers of professionalization and its diversity tokenism to nurture a community that embodies the communal ideals that feminism has long espoused. It is not only professionalized organizations but also grassroots collectives that must invest in solidarity and value accountability. With professionalization uprooting traditional means of community building, leaving radicals to fumble together online, the need for mindful comradery is only heightened. However, online relationships are inherently more distant and prone to miscommunications. It is also much easier for participants to drift away and drop out. I wonder if it is possible to overcome this isolationist tendency in movement culture.

Thus, I conclude this essay on the landscape of third wave vegan feminism in the era of internet technology and nonprofitization with an emphasis on the alienating nature of these new structures. The internet may bring activists together, but it also keeps activists at a distance. Professional decorum and basic neighborliness are difficult norms to maintain between solitary individuals restrained by screens and keyboards. Third wave online activism also brings with it misogynistic trolling, astroturfing, bots, culture clashes, and a variety of other cyber-oriented difficulties that stretch and pull vegan feminists. For older generation activists, these tribulations may be dismissed as "drama" that an activist brings on herself and could easily ignore. But, for many young people, unplugging is not always an accessible or realistic solution. Doing so could risk their complete social isolation, and social isolation is antithetical to sustainable, quality collective action (and mental health). In the present service economy, some are also tied to cyberspaces since an online presence is increasingly required for work. Advice to "ignore the haters" and reprimands to not "feed the trolls" diminish the real psychological difficulties that minorities face online. Cyberbullying is notoriously white supremacist and misogynist. It is also frequently orchestrated. Facebook is known to encourage this violent communication, because intense emotional response to comments can increase a user's screen time (and thus their 
exposure to paid advertisements) (The Daily Show 2018). Nonprofitization, meanwhile, erodes traditional measures of activist congregation. With membership generally relegated to a regular donation or petition-signing, activists today are less likely to come together in physical proximity to discuss tactics, campaign, or protest. Third wave activism thus runs into difficulties with community-building. To remain successful, vegan feminism must counter these negative consequences by creating buffers and breathing room.

\section{Acknowledgements}

The author would like to thank xxx for her valuable and gracious assistance in editing this manuscript.

\section{References}

269life. 2013. Women Forcefully Milked in the Street. Retrieved September 22, 2018 from https://www.youtube.com/watch?v=3R6bqSzAsc8

Adams, Carol. 2000. The Sexual Politics of Meat: A Feminist-Vegetarian Critical Theory. New York: The Continuum Publishing Company.

-----. 1996. "Caring About Suffering: A Feminist Exploration.” In Beyond Animal Rights: A Feminist Caring Ethic for the Treatment of Animals, eds. Josephine Donovan and Carol Adams, 170-196. New York: Continuum.

Adamson, Walter. 2014. Hegemony and Revolution. Brattleboro: Eco Point Books \& Media. Almeida, Paul and Mark Lichbach. 2003. "To the Internet, From the Internet: Comparative Media Coverage of Transnational Protest." Mobilization 8(3) : 249-272.

Barnett, Rosalind and Caryl Rivers. 2004. Same Difference: How Gender Myths Are Hurting Our Relationships, Our Children, and Our Jobs. New York: Basic Books.

Beaman, Lori, Duflo, Esther, Pande, Rohini, and Topalova, Petia. 2012. "Female Leadership Raises Aspirations and Educational Attainment for Girls." Science 1212382.

Beers, Diane. 2006. For the Prevention of Cruelty: The History and Legacy of Animal Rights Activism in the United States. Athens: Ohio University Press.

Bourdieu, Pierre. 1977. Outline of a Theory of Practice. Cambridge: Cambridge University Press.

Bosman, Julie, Matt Stevens, and Jonah Bromwich. 2018. Humane Society C.E.O. Resigns Amid Sexual Harassment Allegations. Retrieved September 22, 2018 from https:/www.nytimes.com/2018/02/02/us/humane-society-ceo-sexual-harassment-.html

Castells, Manuel. 2012. Networks of Outrage and Hope: Social Movements in the Internet Age. Malden: Polity.

Center for Disease Control. 2015. Ages 1-44 by Age Group - All Females. Retrieved June 30, 2018 from https://www.cdc.gov/women/lcod/2015/all-females/index.htm

Chen, Ching-In, Dulani, Jai, and Piepzna-Samarasinha, Leah. Eds. 2011. The Revolution Starts at Home: Confronting Intimate Violence Within Activist Communities. Brooklyn: South End Press.

Cudworth, Erica. 2011. Social Lives with Other Animals: Tales of Sex, Death and Love. New York: Palgrave Macmillan.

Deckha, Maneesha. 2008. "Disturbing Images: PETA and the Feminist Ethics of Animal Advocacy." Ethics and the Environment 13 (2): 35-76.

Dixon, Kitsy. 2014. "Feminist Online Identity: Analyzing the Presence of Hashtag Feminism." Journal of Arts \& Humanities 3 (7): 34-40.

Dworkin, Andrea. 1981. Pornography: Men Possessing Women. New York: Plume. 
Fortune. 2017. These are the Women CEOs Leading Fortune 500 Companies. Retrieved June 30, 2018 from http://fortune.com/2017/06/07/fortune-500-women-ceos/

Earl, Jennifer and Alan Schussman. 2003. "The New Site of Activism: On-line Organizations, Movement Entrepreneurs, and the Changing Location of Social Movement Decision Making." Research in Social Movements 24 : 155-187.

Gaarder, Emily. 2011. Women and the Animal Rights Movement. New Brunswick: Rutgers University Press.

Groves, Julian. 2001. "Animal Rights and the Politics of Emotion.” In Passionate Politics, eds. Jeff Goodwin, James Jasper, and Francesca Polletta, 212-232. Chicago: The University of Chicago Press.

Hall, Lee. 2006. Capers in the Churchyard: Animal Rights Advocacy in the Age of Terror. Darien: Nectar Bat Press.

------. 2010. On Their Own Terms: Bringing Animal-Rights Philosophy Down to Earth. Darien: Nectar Bat Press.

Harding, Kate. 2015. Asking For It: The Alarming Rise of Rape Culture--and What We Can Do about It. Boston: Perseus Books Group.

Harper, Breeze. 2010. "Race as a 'Feeble Matter' in Veganism: Interrogating Whiteness, Geopolitical Privilege, and Consumption Philosophy of 'Cruelty-Free' Products." Journal for Critical Animal Studies 8(3) : 5-27.

-----. 2010. Ed. Sistah Vegan. Brooklyn, NY: Lantern Books.

Healy, Gráinne, Brian Sheehan, and Noel Whelan. 2015. Ireland Says Yes: The Inside Story of How the Vote for Marriage Equality was Won. Sallins: Merrion Press.

Jacobsson, Kerstin and Lindblom, Jonas. 2013. "Emotion Work in Animal Rights Activism." Acta Sociologica 56(1) : 55-68.

Jasper, James and Poulsen, Jane. 1995. "Recruiting Strangers and Friends: Moral Shocks and Social Networks in Animal Rights and Anti-Nuclear Protests." Social Problems 42 : 493512.

Jensen, Robert. 2007. Getting Off: Pornography and the End of Masculinity. Cambridge: South End Press.

Kean, Hilda. 1998. Animal Rights. London: Reaktion Books.

Kheel, Marti. 1985. "Speaking the Unspeakable: Sexism in the Animal Rights Movement." Feminists for Animal Rights Newsletter 2(1) : 1-6.

------. 1993. "From Heroic to Holistic Ethics." In Ecofeminism: Ethics and Action, ed. Greta Gaard, 243-244. Philadelphia: Temple University.

Ko, Aph and Syl Ko. 2017. Aphro-ism. Brooklyn: Lantern.

Lawson, Ronald and Stephen Barton. 1980. "Sex Roles in Social Movements." Signs 6(2) : 230247.

MacKinnon, Catherine. 1989. Toward a Feminist Theory of the State. Cambridge: Harvard University Press.

McCarthy, John and Mayer Zald. 1973. The Trend of Social Movements in America: Professionalization and Resource Mobilization. Morristown: General Learning Press.

McRobbie, Angela. 2005. "Post-feminism and Popular Culture." In Media and Cultural Theory, eds. James Curran and David Morley, 59-70. New York: Routledge.

Meyer, David and Suzanne Staggenborg. 1996. "Movements, Countermovements, and the Structure of Political Opportunity." American Journal of Sociology 101(6) : 1628-1660. 
Mirk, Sarah. 2015. "Liberal Problems." Popaganda [Podcast]. Retrieved September 22, 2018 from: https://soundcloud.com/bitch-media/wtf-peta

Mottl, Tahi. 1980. "The Analysis of Countermovements." Social Problems 27(5) : 620-635.

Omond, Tasmin. 2012. Power, Oppression and Abuse: Performing Animal Tests. Retrieved September 22, 2018 from https://www.fightinganimaltesting.com/our-blog/poweroppression-and-abuse-performing-animal-tests-2/

Pendergrast, Nicholas. 2014. A Sociological Examination of the Contemporary Animal Advocacy Movement. Dissertation. Perth: Curtin University.

Reyer, Jo. 2002. "More than One Feminism: Organizational Structure and the Construction of Collective Identity." In Social Movements, eds. David Meyer, Nancy Whittier, and Belinda Robnett, 171-184. New York: Oxford University Press.

Robnett, Belinda. 1996. "African-American Women in the Civil Rights Movement, 1954-1965." American Journal of Sociology 101(6) : 1661-1693.

Socha, Kim. 2013. "The 'Dreaded Comparisons' and Speciesism: Leveling the Hierarchy of Suffering." In Confronting Animal Exploitation: Grassroots Essays on Liberation and Veganism, eds. Kim Socha and Sarahjane Blum, 223-240. Jefferson: McFarland \& Company, Inc., Publishers.

Smith, Andrea. 2007. "Introduction." In The Revolution Will Not Be Funded: Beyond the NonProfit Industrial Complex, ed. INCITE! Women of Color Against Violence, 1-20. Cambridge: South End Press.

Staggenborg, Suzanne. 2010. "Research on Social Movement Coalitions." In Strategic Alliances, eds. Nella Van Dyke and Holly McCammon, 316-329. Minneapolis: University of Minnesota Press.

Szymanski, Dawn, Lauren Moffitt, and Erika Carr. 2011. "Sexual Objectification of Women: Advances to Theory and Research." The Counseling Psychologist 39(1) : 6-38.

The Daily Show. 2018. Facebook Cashes in on Conflict. Retrieved June 30, 2018 from https://www.youtube.com/watch? $\mathrm{v}=\mathrm{XxVFssljoLY}$

Thelandersson, Fredrika. 2014. "A Less Toxic Feminism: Can the Internet Solve the Age Old Question of How to Put Intersectional Theory into Practice?" Feminist Media Studies $14(3)$ : 527-530.

United Nations. 2008. How Widespread is Violence Against Women? Retrieved on June 30, 2018 from http://www.un.org/en/women/endviolence/pdf/VAW.pdf

UN Women. 2018. Facts and Figures. Retrieved on June 30, 2018 from http://www.unwomen.org/en/what-we-do/leadership-and-political-participation/factsand-figures

Violence Policy Center. 2017. More Than 1,600 Women Murdered by Men in One Year, New Study Finds. Retrieved June 30, 2018 from http://www.vpc.org/press/more-than-1600women-murdered-by-men-in-one-year-new-study-finds-3/ 